\title{
Serum Cholesterol Level and the Rate of Progression to Renal Failure
}

To the Editor:

I read with interest the article by Iseki et al. (Clin Exp Nephrol 1998;2:18-24) on serum cholesterol and risk of end-stage renal diseases, ${ }^{1}$ which suggests that high levels of serum cholesterol may be a risk factor for end-stage renal diseases, but may not be an independent risk factor. Their study showed that hypercholesterolemia failed to remain a risk factor for end-stage renal disease after controlling for age, sex, hematuria, and proteinuria.

When I was a research fellow of the Second Department of Internal Medicine, Kyushu University Medical School, I conducted an experimental study with the help of some colleagues that showed that the treatment of hypercholesterolemia with a specific inhibitor of 3-hydroxy-3-methylglutaryl coenzyme A reductase, lovastatin, reduced both hypercholesterolemia and proteinuria, and weakened the progression of glomerulosclerosis in rats with doxorubicin-induced nephropathy. ${ }^{2}$ We then conducted an epidemiologic study to investigate the relationship between serum cholesterol levels and the rate of progression to renal failure (the regression line was obtained from the reciprocal serum creatinine and observation time; the average observation time was 4.1 years), among 104 patients with chronic renal failure. ${ }^{3}$ We found a significant positive relationship between serum cholesterol levels and the rate of progression to renal failure, even after controlling for the degree of proteinuria (Table 1).

The results of the study by Iseki et al., and our studies, suggest that hypercholesterolemia can advance existing glomerulosclerosis, but may not initiate renal injury.
Table 1. Multiple regression analysis of factors related to progression of renal deterioration. ${ }^{3}$

\begin{tabular}{lccc}
\hline Factors & $\begin{array}{c}\text { Parameter } \\
\text { estimate } \\
\left(\times 10^{2}\right)\end{array}$ & $\begin{array}{c}\text { SEM } \\
\left(\times 10^{2}\right)\end{array}$ & Pvalue \\
\hline Total cholesterol (mg/dL) & 0.035 & 0.014 & 0.01 \\
Urinary protein (score) & 3.479 & 1.693 & 0.04 \\
\hline
\end{tabular}

Score, semiquantitative score such that levels of urinary protein excretion $<15 \mathrm{mg} / \mathrm{dL}=0$, from 15 to $29 \mathrm{mg} / \mathrm{dL}=0.5$, from 30 to 99 $\mathrm{mg} / \mathrm{dL}=1$, from 100 to $299 \mathrm{mg} / \mathrm{dL}=2$, from 300 to $999 \mathrm{mg} / \mathrm{dL}=3$, and $\geq 1000 \mathrm{mg} / \mathrm{dL}=4$.

Masakazu Washio, MD

Kitakyushu Tsuyazaki Hospital

Watari 1693, Fukuoka 811-3307

Japan

\section{REFERENCES}

1. Iseki K, Ikeymiya Y, Fukiyama K. Serum cholesterol and risk of end-stage renal diseases in a cohort of mass screening. Clin Exp Nephrol 1998;2:18-24.

2. Washio M, Nanishi F, Okuda S, Onoyama K, Fujishima M. Importance of early initiation of antihyperlipidemic treatment for the prevention of experimental progressive renal failure. Curr Ther Res 1995;56:144-151.

3. Washio M, Okuda S, Ikeda M, Hirakata H, Nanishi F, Onoyama K, Yoshimura T, Fujishima M. Hypercholesterolemia and the progression of the renal dysfunction in chronic renal failure patients. J Epidemiol 1996;6:172-177. 